\title{
Lipid Mediators and Human Leukemic Blasts
}

\author{
Rémi Fiancette, ${ }^{1}$ Christelle Vincent-Fabert, ${ }^{1}$ Estelle Guerin, ${ }^{2}$ \\ Franck Trimoreau, ${ }^{2}$ and Yves Denizot ${ }^{1}$ \\ ${ }^{1}$ Centre National de la Recherche Scientifique, CNRS UMR 6101, Faculté de Médecine, Université de Limoges, \\ 2 rue Dr. Marcland, 87025 Limoges, France \\ ${ }^{2}$ Laboratoire d'Hématologie, CHU Dupuytren, 87042 Limoges, France
}

Correspondence should be addressed to Yves Denizot, yves.denizot@unilim.fr

Received 16 June 2010; Revised 23 September 2010; Accepted 24 September 2010

Academic Editor: Aurelio Lorico

Copyright (C) 2011 Rémi Fiancette et al. This is an open access article distributed under the Creative Commons Attribution License, which permits unrestricted use, distribution, and reproduction in any medium, provided the original work is properly cited.

\begin{abstract}
Some of the most potent inflammatory mediators share a lipid origin. They regulate a wide spectrum of cellular processes including cell proliferation and apoptosis. However, the precise roles and ways (if any) in which these compounds impact the growth and apoptosis of leukemic blasts remain incompletely resolved. In spite of this, significant advances have been recently made. Here we briefly review the current knowledge about the production of lipid mediators (prostaglandins, leukotrienes, plateletactivating factor) by leukemic blasts, the enzymatic activities (phospholipase $\mathrm{A}_{2}$, cyclooxygenases, lipoxygenases) involved in their productions and their effects (through specific membrane bound receptors) on the growth, and apoptosis of leukemic blasts.
\end{abstract}

\section{Introduction}

Some of the most potent inflammatory mediators share a lipid origin. The action of phospholipase $\mathrm{A}_{2}\left(\mathrm{PLA}_{2}\right)$ on membrane phospholipids produces free fatty acids such as arachidonic acid (AA) and the phospholipid backbone. To the former belongs eicosanoids (such as prostaglandins, prostacyclin, thromboxane, and leukotrienes) through the cyclooxygenase (COX) and lipoxygenase (LOX) pathways; and to the latter, platelet-activating factor (PAF) (Figure 1) $[1,2]$. While countless studies have highlighted the actions of eicosanoids and PAF on normal human mature myeloid and lymphoid cells (from hematopoietic progenitors to mature blood cells), their effects on leukemic blasts are poorly documented, and furthermore, their putative involvements during leukemic diseases remain almost speculative. This paper focuses on new results about lipid mediators and human leukemic blast cells from acute myeloid (AML) and acute lymphoid (ALL) patients. The vast majority of results reported previously have been obtained with AML blasts without maturation according to the classification system of the World Health Organization, thus corresponding to the past AML $\mathrm{M}_{0-2}$ nomenclature.

\section{PLA 2, PLA $_{2}$ Receptors, and Human Leukemic Blasts}

$\mathrm{PLA}_{2}$ catalyzes the hydrolysis of the $s n-2$ position of membrane glycerophospholipids to liberate the eicosanoid precursor AA (Figure 1) [3, 4]. Three distinct families are documented: low molecular weight soluble forms of $\mathrm{PLA}_{2}\left(\mathrm{sPLA}_{2}\right) ; \mathrm{Ca}^{2+}$-dependent high molecular weight $\mathrm{PLA}_{2}$ (cytoplasmic PLA $2, \mathrm{CPLA}_{2}$ ); cytoplasmic $\mathrm{Ca}^{2+}$-independent high molecular weight $\mathrm{PLA}_{2}\left(\mathrm{iPLA}_{2}\right)$. In addition, the $\mathrm{PLA}_{2}$ family is implicated in several biological processes such as inflammation and host defence $[3,4]$. Nine isoenzymes have been identified. The cPLA $A_{2}$ family consists of four members, with $\mathrm{CPLA}_{2}$-IVA being the central regulator of the stimuluscoupled cellular AA release $[3,4]$. The iPLA $_{2}\left(\mathrm{PLA}_{2}-\mathrm{VI}\right)$ plays a major role in phospholipid remodelling. Freshly isolated leukemic blasts from AML and ALL patients express mRNA from four out of five cPLA (PLA $_{2}$-IVA, $\mathrm{PLA}_{2}$-IVB, PLA $\mathrm{P}_{2}-$ IVC, and $\left.\mathrm{PLA}_{2}-\mathrm{VI}\right)$ and six out of nine $\mathrm{PLA}_{2}\left(\mathrm{PLA}_{2}-\mathrm{IB}\right.$, $\mathrm{PLA}_{2}$-IIA, PLA $\mathrm{PL}_{2}$-IID, $\mathrm{PLA}_{2}-\mathrm{V}, \mathrm{PLA}_{2}-\mathrm{X}$, and $\mathrm{PLA}_{2}$-XII) and that transcript levels exhibit wide variations as compared to control blood mononuclear cells [5]. One of the most notable findings is that AML and ALL blasts express high 
amounts of $\mathrm{PLA}_{2}-\mathrm{VI}$ and $\mathrm{PLA}_{2}-\mathrm{X}$. This could be extremely significant as these two enzymatic activities play a major role in AA release for the generation of COX- and LOXderived lipid mediators. Thus, AML and ALL blasts have the potential to express multiple isoforms of $\mathrm{CPLA}_{2}$ and sPLA $_{2}$ which could be of importance given the role of these enzymes in inflammation, generation of lipid mediators, anticoagulant activity, and bacterial infection. Biological activities of $\mathrm{PLA}_{2}$ are attributed to their enzymatic capacity to hydrolyze membrane phospholipids. However, in addition $\mathrm{sPLA}_{2}$ exerts various biological proinflammatory responses through the binding to the cell surface $\mathrm{PLA}_{2}$ receptor $\left(\mathrm{PLA}_{2}\right.$ R) [6]. Of interest is the functional membrane $\mathrm{PLA}_{2}-\mathrm{R}$ found on AML and ALL blasts strengthening a role for PLA signalling in these cells (Denizot and coll., in preparation). The concept of anti-inflammation is currently evolving with the discovery of endogenous inhibitory circuits, such as the annexin (ANX) system, that are important in the control of the host inflammatory response [7]. ANX-1

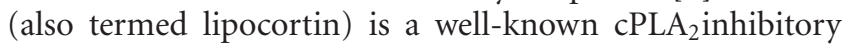
protein produced by and acting on several blood cell types such as monocytes/macrophages and polymorphonuclear leukocytes. The ANX-1 protein level is markedly elevated in AML blasts [8], where ANX-1 is not only considered as an anti-inflammatory and tumor suppressor molecule (through its inhibiting $\mathrm{cPLA}_{2}$ activity) but also as one of the "eat-me" signals on apoptotic cells to be recognised and ingested by phagocytes [8]. It is, thus, tempting to speculate that $\mathrm{PLA}_{2}$ R and ANX-1 might take an important place in the "yin" and the "yang" of the inflammatory reaction occurring in AML blasts. During the past decade, considerable research has been directed towards the identification of new biological targets for AML treatment. It is tempting to suggest that $\mathrm{PLA}_{2}-\mathrm{R}$ antagonists might be one of them especially with respect to the emerging roles for PLA 2 enzymes in cancer [9].

\section{COX and Human Leukemic Blasts}

In the COX pathway, $\mathrm{AA}$ is converted to $\mathrm{PGH}_{2}$ by $\mathrm{COX}-1$ or COX-2 enzymes. $\mathrm{PGH}_{2}$ is subsequently metabolised to generate different prostanoids, depending on the enzymes expressed in the cell [1]. The COX-1 isoform is typically constitutively expressed unlike the inducible COX-2 one. The growth-promoting properties of COX-2 in physiological responses are diverted in malignancies [10]. COX-1 and COX-2 transcripts are documented in AML and ALL blasts [11], but only the COX-1 protein is found. Similarly COX1 , but not the COX-2 protein, is detected in human primary promyelocytic blasts during differentiation [12]. In fact, the AML and ALL blasts can express the COX-2 protein in response to lipopolysaccharide (LPS) but only in the subsets of patients [13]. The ability of ALL blasts to express COX2 is consistent with its presence in stimulated normal B-cells and in chronic lymphocytic leukaemia (CLL) B-cells $[14,15]$. The production of COX-2 in response to LPS by AML blasts is consistent with data reporting that LPS is a potent inductor of COX-2 in mature monocytes/macrophages [16] and that stimulated HL-60 cells (an AML cell line with an $\mathrm{M}_{2 / 3}$ subtype) express COX-2 [17]. The heterogeneity in the LPSstimulated COX-2 expression by AML blasts is not linked to a different Toll-like receptor (TLR2 or TLR4) expression [13] and remains an open question that requires further evaluation.

\section{PGE $_{2}$, EP Receptors, and Human Leukemic Blasts}

Following the action of the COX pathway, $\mathrm{PGH}_{2}$ is subsequently metabolized to generate different prostanoids, depending on the enzymes expressed in the cell. Prostanoids include prostacyclin $\left(\mathrm{PGI}_{2}\right)$, thromboxane $\mathrm{A}_{2}\left(\mathrm{TXA}_{2}\right)$, and prostaglandin $\mathrm{E}_{2}\left(\mathrm{PGE}_{2}\right)$, synthesized by a $\mathrm{PGI}_{2}$ synthase, a TXA synthase, and a PGE synthase, respectively [1]. Three PGE synthase isoforms exist: inducible membrane-bound PGE synthase-1 (mPGES-1), constitutive membrane-bound PGE synthase-2, and cytosolic PGE synthase. In addition, the ability of $\mathrm{PGE}_{2}$ to regulate the immune system has been widely explored [18]. Data reporting the ability of $\mathrm{PGE}_{2}$ to modulate several functions in mature blood cells such as monocyte-macrophages, dendritic cells, and $\mathrm{T}$ and $B$ lymphocytes can be readily found. Human AML and ALL blasts spontaneously release $\mathrm{PGE}_{2}$ [11], with $\mathrm{PGE}_{2}$ synthesis being inhibited by indomethacin. Transcripts for mPGES-1 are detected in AML and ALL blasts suggesting its role in $\mathrm{PGE}_{2}$ synthesis (Denizot and coll., unpublished results). $\mathrm{PGE}_{2}$ effects are well known and are mediated through interactions with four distinct membrane-bound G-protein-coupled $\mathrm{EP}$ receptors: $\mathrm{EP}_{1}, \mathrm{EP}_{2}, \mathrm{EP}_{3}$, and $\mathrm{EP}_{4}$ [18]. $\mathrm{EP}_{2}$ and $\mathrm{EP}_{4}$ are coupled to $\mathrm{G}_{5}$ and stimulate cAMP production which leads to gene regulation. $\mathrm{EP}_{3}$ is coupled to $\mathrm{G}_{\mathrm{i}}$ and inhibit cAMP synthesis. $\mathrm{EP}_{1}$ is coupled to $\mathrm{G}_{\mathrm{q} / \mathrm{p}}$, and ligand binding induces intracellular calcium level variations. Functional $\mathrm{EP}_{2}$ receptors are present on $\mathrm{AML}$ and $\mathrm{ALL}$ blasts $[19,20]$. In contrast to $\mathrm{EP}_{2}$ receptors, no functional $\mathrm{EP}_{1}, \mathrm{EP}_{3}$, and $\mathrm{EP}_{4}$ receptors are found [20]. In view of the potentially important role of $\mathrm{PGE}_{2}$ in processes of cancer and leukocyte maturation and function, $\mathrm{PGE}_{2}$ effects have been investigated on blast cell proliferation and apoptosis. $\mathrm{PGE}_{2}$ enhances the spontaneous and LPS-stimulated growth of AML blasts without affecting their apoptosis [11]. In summary, AML and ALL blasts secrete $\mathrm{PGE}_{2}$. A role for $\mathrm{PGE}_{2}$ as a compound contributing to AML cell proliferation (via an $\mathrm{EP}_{2}$ receptor-mediated pathway) can be hypothesized.

\section{TXA $_{2}, \mathbf{P G I}_{2}$, and Human Leukemic Blasts}

$\mathrm{TXA}_{2}$ and $\mathrm{PGI}_{2}$ are two other potent COX metabolites. $\mathrm{TXA}_{2}$ is produced abundantly by platelets upon exposure to injured blood vessels and thus exhibits potent plateletaggregating and vessel-contracting activities. $\mathrm{PGI}_{2}$ is the major COX-derived product of AA formed in the macrovascular endothelium and is a potent inhibitor of platelet aggregation activity and vessel vasodilatation activity [21]. AML and ALL blasts express low levels of TX synthase transcripts compared to normal blood mononuclear cells (Denizot and coll., unpublished results) and additionally produce very 


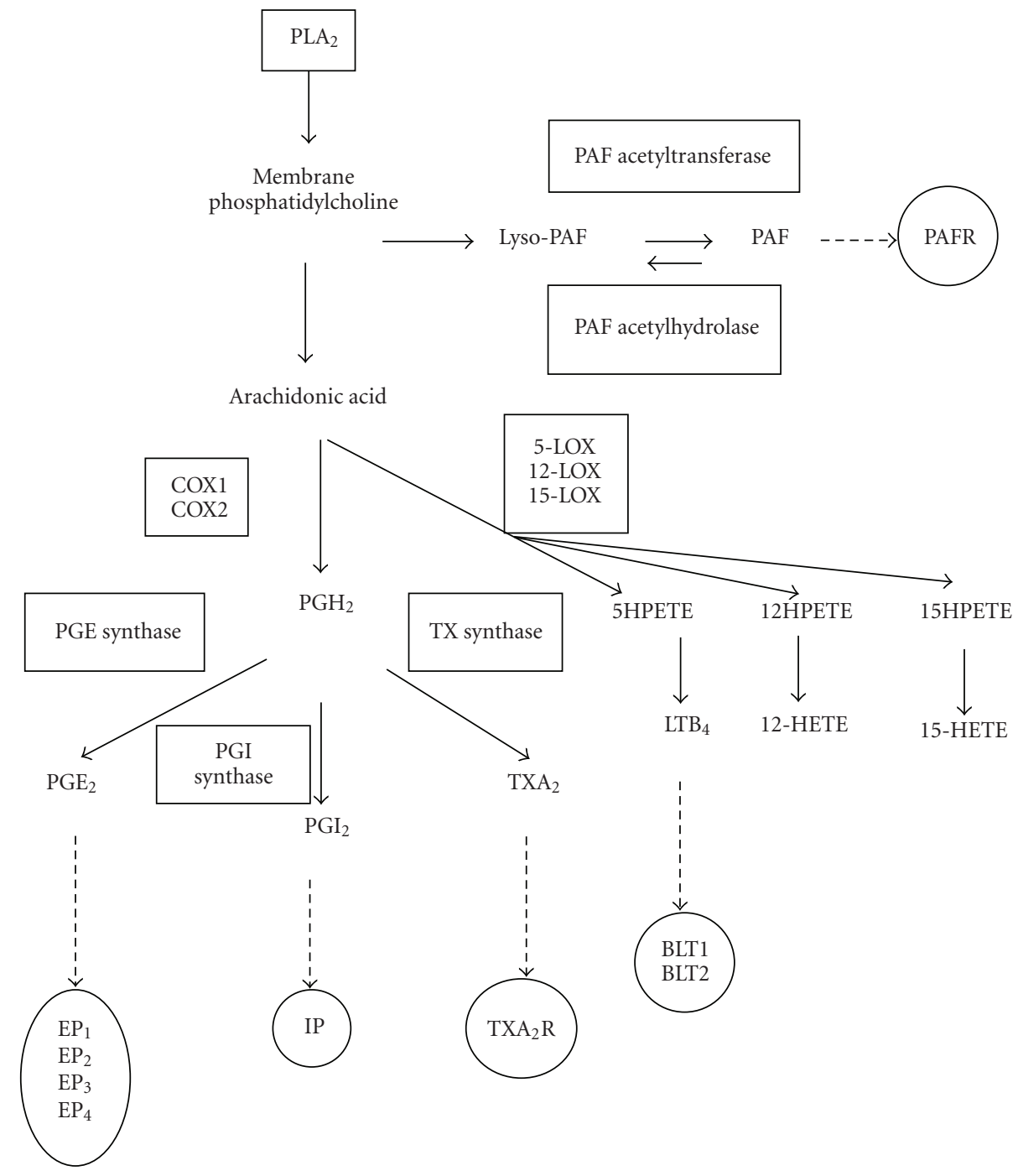

FIGURE 1: Simplified representation of the pathways involved in eicosanoid and platelet-activating factor formation and signal transduction. Enzymatic activities and receptors are in rectangles and ovals, respectively. PLA 2 , phospholipase $\mathrm{A}_{2}$; COX, cyclooxygenase; LOX, lipoxygenase; $\mathrm{PGH}_{2}$, prostaglandin $\mathrm{H}_{2} ; \mathrm{PGE}_{2}$, prostaglandin $\mathrm{E}_{2} ; \mathrm{PGI}_{2}$, prostacyclin; $\mathrm{TXA}_{2}$, thromboxane $\mathrm{A}_{2}$; HPETE, hydroperoxyeicosatetraenoic acid; $\mathrm{LTB}_{4}$, leukotriene $\mathrm{B}_{4}$; HETE, hydroxyeicosatetraenoic acid; PAF, platelet-activating factor; PAFR, PAF receptor; $\mathrm{EP}_{1-4}$, subtype 1-4 of the $\mathrm{PGE}_{2}$ receptor; $\mathrm{IP}, \mathrm{PGI}_{2}$ receptor; $\mathrm{TXA}_{2} \mathrm{R}, \mathrm{TXA}_{2}$ receptor; $\mathrm{BLT}_{1-2}$, subtype 1 and 2 of the $\mathrm{LTB}_{4}$ receptor.

low amounts of $\mathrm{TXA}_{2}$ in response to a calcium ionophore stimulation [22]. HL-60 cells have also been shown to release $\mathrm{TXA}_{2}$, but only after induction of differentiation $[23,24]$. PGI synthase transcripts are absent in AML and ALL blasts, a result similar to that found in control blood mononuclear cells (Denizot et coll., unpublished results). In accordance with the absence of PGI transcripts in AML and ALL blasts, calcium ionophore-stimulated blasts do not release $\mathrm{PGI}_{2}$ (Denizot et coll., unpublished results). TXA and $\mathrm{PGI}_{2}$ act through membrane receptors (namely $\mathrm{TXA}_{2} \mathrm{R}$ and IP for TXA $A_{2}$ and $\mathrm{PGI}_{2}$, resp.) $[25,26]$. As to whether AML and ALL blasts release TXA 2 and $\mathrm{PGI}_{2}$, they express levels of transcripts for $\mathrm{TXA}_{2} \mathrm{R}$ and IP equal or higher than those found in control blood mononuclear cells [27]. $\mathrm{TXA}_{2} \mathrm{R}$ and IP receptors belong to the class of Gs-proteincoupled receptors $[25,26]$. Stimulation of leukemic blasts with U-46619, the TXA 2 receptor agonist U-46619, and $\mathrm{PGI}_{2}$ stimulate in a dose-dependant manner cAMP synthesis from leukemic blasts showing the presence of functional TXA 2 and IP receptors, respectively [27]. However, simulation of leukemic blast with U-46619 and $\mathrm{PGI}_{2}$ has no effect on their growth and apoptosis rate. At the present time the physiological meaning of functional $\mathrm{TXA}_{2} \mathrm{R}$ and IP receptors on leukemic blasts remains an open question. In conclusion, among the various COX-derived metabolites of AA only $\mathrm{PGE}_{2}$ has, thus, a significant effect on the growth of AML blast cells [11], and none of them affect their apoptosis rate.

\section{LOX and Human Leukemic Blasts}

The LOX pathway involves the conversion of AA to 5-, 12-, or 15-hydroperoxyeicosatetraenoic acids (HPETE) by 


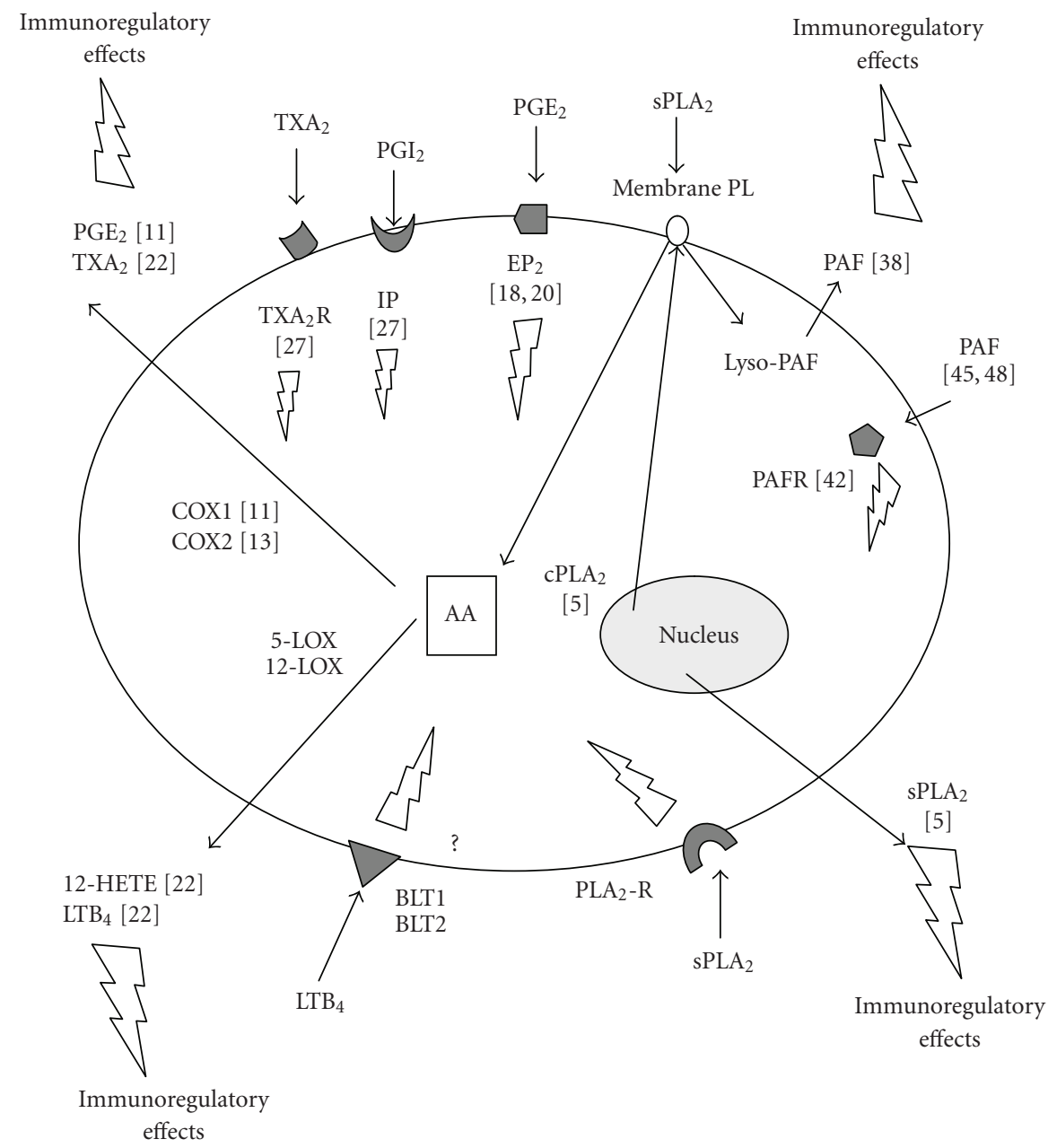

FIGURE 2: Simplified representation of the relationships between lipid mediators and leukemic blasts. Leukemic cells express several cPLA 2 and $\mathrm{SPLA}_{2}$. COX activities can metabolise AA into $\mathrm{PGE}_{2}$ and $\mathrm{TXA}_{2}$. LOX activities can metabolise AA into LTB 4 and 12-HETE. Leukemic cells can release PAF. Functional TXA $\mathrm{TP}_{2}, \mathrm{IP}, \mathrm{EP}_{2}, \mathrm{PAF}$, and $\mathrm{PLA}_{2}$ receptors are found on leukemic cells. BLT1 and BLT2 transcripts are detected suggesting (?) $\mathrm{LTB}_{4}$ receptors. The immunoregulatory effects of lipid mediators are currently speculative except for the role of PGE 2 on $\mathrm{AML}$ blast growth. Related references are in square brackets.

5-, 12-, or 15-LOX, respectively, HPETEs being rapidly metabolized to 5-, 12, or 15-hydroxyeicosatetraenoic acids (HETE). 5-HPETE could be dehydrated into leukotriene A4 $\left(\mathrm{LTA}_{4}\right)$, which was enzymatically hydrolyzed to $\mathrm{LTB}_{4}$ (Figure 1) [1]. The ability of $\mathrm{LTB}_{4}, 12$-HETE, and 15HETE to regulate important functions of the immune system has been widely explored. These compounds activate various blood cell types and stimulate their proinflammatory cytokine productions [28-30], indicating an ability of $\mathrm{LTB}_{4}$, 12-HETE, and 15-HETE to augment and prolong tissue inflammation. Leukemic blasts express 5-LOX, 12-LOX, and 15-LOX transcripts, their expression being in general lower than in blood mononuclear cells from a healthy donor [22, $31,32]$. Leukemic blasts produce in vitro lower amounts of $\mathrm{LTB}_{4}$ than healthy donors $[22,31,33]$. This reduced capacity of AML blasts to produce $\mathrm{LTB}_{4}$ is located at the 5LOX level. Stimulated leukemic blasts produce 12-HETE but not 15-HETE [22]. The various LOX-derived metabolites of
AA regulate a wide spectrum of cellular processes including cell proliferation and apoptosis. 12-HETE and 15-HETE stimulate the proliferation and differentiation of normal CD34 ${ }^{+}$cells [34]. $\mathrm{LTB}_{4}$ induces proliferation and exerts an antiapoptotic effect on blood CD34 ${ }^{+}$cells [35]. However, $\mathrm{LTB}_{4}, 12$-HETE, and 15 HETE have no effect on the growth and apoptosis rate of AML and ALL blasts in vitro [22]. As to whether receptors for 12-HETE and 15-HETE remain to be molecularly identified, two G-protein-coupled seven transmembrane domain receptors for $\mathrm{LTB}_{4}$ were identified: BLT1 and BLT2 [36]. Amounts of BLT1 transcripts are similar in AML and ALL blasts as well as control blood mononuclear cells, while amounts of BLT2 transcripts are markedly higher [22]. At this time the physiological meaning (if any) of BLT1 and BLT2 transcripts in AML and ALL blasts remains an open question. A similar question exists for the significance of $\mathrm{LTB}_{4}$ - and 12-HETE-derived leukemic blasts. One might suggest that these compounds could initiate, augment, and 
prolong tissue inflammation and damages by affecting the cytokine network, but currently no studies have provided evidences in support of this.

\section{PAF, PAFR, and Human Leukemic Blasts}

PAF is a phospholipid mediator that sparks off a wide range of immunoregulatory activities on blood cells such as polymorphonuclear neutrophils, eosinophils, monocytes, macrophages, and lymphocytes [2]. PAF is released in vitro from several leukemic cell lines of B and T origin [37] as well as from freshly isolated neoplastic cells of leukemic patients [38]. However, in spite of experimental evidence reporting its in vitro release from leukemic cells, no clinical studies provide evidences to support this view in vivo. In contrast, decreased levels of PAF are found in the blood of patients with lymphoid and nonlymphoid hematologic malignancies [39]. Blood PAF levels are regulated by an acetylhydrolase

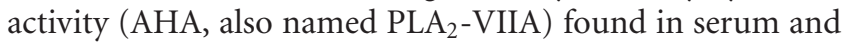
plasma. Plasma AHA is not altered in leukemic patients [39] suggesting a lowered PAF production by leukemic cells rather than an increased PAF catabolism. PAF acts through membrane and nuclear PAF receptors (PAFR) that belong to the G-protein-coupled family [40,41]. As to whether membrane PAFR is found on AML and ALL cells [42, 43], intracellular ones were detected [42]. Studies report that mature monocytes, macrophages, polymorphonuclear leukocytes, and B lymphocytes produce cAMP in response to PAF $[44,45]$. This is not the case for AML and ALL blasts [46]. PAF modulates $\mathrm{Ca}^{2+}$ flux through a Gq-proteinmediated pathway [47]. The $\mathrm{Gq}$ proteins mediate their effects by activating phospholipase $\mathrm{C}$ and thus, generating second messengers, inositol-1,4,5-triphosphate (IP3) and diacylglycerol, thereby leading to the activation of protein kinase $\mathrm{C}$ and the mobilisation of intracellular calcium. PAF stimulates in a receptor-dependent process $\mathrm{Ca}^{2+}$ flux from AML and ALL blasts showing the presence of functional PAFR [48] and highlighting that PAFR signals via the Gq instead of the Gi/Gs protein pathways. Hence, the role of PAF in leukemic blasts still remains an open question. PAF has no significant effect on growth and apoptosis rate in these cells [49] suggesting that PAF is not an important modulator of blast cell physiology. The lack of PAF effect is linked to low levels of PAFR in AML and ALL blasts compared to those found in mature leukocytes [49]. Further, strengthening this issue, the differentiation of HL-60 cells towards the macrophage phenotype is associated with the induction of PAFR gene expression. Thus, PAFR mRNA accumulation is correlated to the induction and development of specific PAF responsiveness [50]. Recently WEB-2170, a PAFR antagonist, has been reported to induce apoptosis in AML cells [51, 52]. In fact, WEB-2170 does not behave as a pure PAFR but instead as an inverse agonist leading to a marked cytoplasmic increase of PTEN proteins (PTEN is a protein/phosphoinositide phosphatase regulating the PI3K/Akt signaling pathway). Consequently, these recent results [49, $51,52]$ support the view that PAF has probably no significant role in the growth and apoptosis of leukemic blasts.

\section{Conclusion}

Data reporting our knowledge concerning the enzymatic activities (such as $\mathrm{PLA}_{2}$, LOX, COX) implicated in lipid mediator synthesis and their receptors on AML and ALL blasts are schematised in Figure 2. Aberrant expression of several PLA $\mathrm{P}_{2}$ enzymes is common place in tumors derived from many different organ sites [9]. Numerous studies report that altered AA metabolism in a solid tumor microenvironment has a profound impact on the pathogenesis of tumor development [1]. A multitude of biological activities of PAF are evidenced both on the normal cell as well as on their cancer counterpart [2]. There is evidence, however, that it is not the case for leukemic blast cells. Among the various proinflammatory lipid molecules so far tested (PAF, $\mathrm{PGE}_{2}, \mathrm{PGI}_{2}$, $\mathrm{TXA}_{2}, \mathrm{LTB}_{4}, 12$-HETE, 15-HETE), none of them exhibit any role on leukemic blast apoptosis despite the expression of functional receptors (PAFR, $\mathrm{EP}_{2}$, IP, $\mathrm{TXA}_{2} \mathrm{R}$ ). Among the various compounds so far tested only $\mathrm{PGE}_{2}$ clearly demonstrated a potential role in AML cell growth in vitro. However, it is difficult to compare the $\mu \mathrm{M}$ amounts of $\mathrm{PGE}_{2}$ used in most of the in vitro studies with the $\mathrm{fM}$ amounts of $\mathrm{PGE}_{2}$ found in the blood at steady state conditions. Studies showing the effects of continuous addition or infusion of low doses of $\mathrm{PGE}_{2}$ (which seems to be a more relevant protocol of stimulation to obtain information for the in vivo effects of $\mathrm{PGE}_{2}$ ) are extremely rare. Moreover, data obtained in vivo and in vitro are sometimes discordant. In fact, there is absolutely no evidence that $\mathrm{PGE}_{2}$ is implicated in the growth of AML blasts in vivo. Thus, in conclusion the biological effects of eicosanoid and PAF are particularly important in immunity and inflammation. Though their roles are well known in numerous pathology and cancers, no such role is currently known for leukemic blast growth.

\section{Conflict of Interests}

The authors have no relevant conflict of interest.

\section{Acknowledgments}

This work was supported in part by a grant from "La ligue Contre le Cancer, Comité de la Corrèze et de la HauteVienne," "Conseil Régional du Limousin", and "Le Lions Club de la Corrèze, Zone 33 District 103 Sud." C. VincentFabert was supported by a grant from the Association pour la Recherche sur le Cancer (ARC).

\section{References}

[1] C. A. C. Hyde and S. Missailidis, "Inhibition of arachidonic acid metabolism and its implication on cell proliferation and tumour-angiogenesis," International Immunopharmacology, vol. 9, no. 6, pp. 701-715, 2009.

[2] Y. Denizot, L. Guglielmi, M. Donnard, and F. Trimoreau, "Platelet-activating factor and normal or leukaemic haematopoiesis," Leukemia and Lymphoma, vol. 44, no. 5, pp. 775-782, 2003.

[3] I. Kudo and M. Murakami, "Phospholipase $A_{2}$ enzymes," Prostaglandins and Other Lipid Mediators, vol. 68-69, pp. 3-58, 2002. 
[4] G. Lambeau and M. H. Gelb, "Biochemistry and physiology of mammalian secreted phospholipases $\mathrm{A}_{2}$," Annual Review of Biochemistry, vol. 77, pp. 495-520, 2008.

[5] R. Fiancette, C. Vincent, M. Donnard et al., "Genes encoding multiple forms of phospholipase $\mathrm{A}_{2}$ are expressed in immature forms of human leukemic blasts," Leukemia, vol. 23, no. 6, pp. 1196-1199, 2009.

[6] K. Hanasaki and H. Arita, "Phospholipase $A_{2}$ receptor: a regulator of biological functions of secretory phospholipase $\mathrm{A}_{2}$," Prostaglandins and Other Lipid Mediators, vol. 68-69, pp. 71-82, 2002.

[7] L. Parente and E. Solito, "Annexin 1: more than an antiphospholipase protein," Inflammation Research, vol. 53, no. 4, pp. 125-132, 2004.

[8] C. López-Pedrera, J. M. Villalba, E. Siendones et al., "Proteomic analysis of acute myeloid leukemia: identification of potential early biomarkers and therapeutic targets," Proteomics, vol. 6, pp. S293-S299, 2006.

[9] K. F. Scott, M. Sajinovic, J. Hein et al., "Emerging roles for phospholipase $\mathrm{A}_{2}$ enzymes in cancer," Biochimie, vol. 92, no. 6, pp. 601-610, 2010.

[10] T. D. Warner and J. A. Mitchell, "Cyclooxygenases: new forms, new inhibitors, and lessons from the clinic," FASEB Journal, vol. 18, no. 7, pp. 790-804, 2004.

[11] V. Truffinet, M. Donnard, C. Vincent et al., "Cyclooxygenase1 , but not -2 , in blast cells of patients with acute leukemia," International Journal of Cancer, vol. 121, no. 4, pp. 924-927, 2007.

[12] B. Rocca, R. Morosetti, A. Habib et al., "Cyclooxygenase1 , but not -2 , is upregulated in NB4 leukemic cells and human primary promyelocytic blasts during differentiation," Leukemia, vol. 18, no. 8, pp. 1373-1379, 2004.

[13] C. Vincent, M. Donnard, D. Bordessoule, P. Turlure, F. Trimoreau, and Y. Denizot, "Cyclooxygenase-2 (Cox-2) and blast cells of patients with acute leukemia," Leukemia Research, vol. 32, no. 4, pp. 671-673, 2008.

[14] E. P. Ryan, S. J. Pollack, T. I. Murant, S. H. Bernstein, R. E. Felgar, and R. P. Phipps, "Activated human B lymphocytes express cyclooxygenase-2 and cyclooxygenase inhibitors attenuate antibody production," Journal of Immunology, vol. 174, no. 5, pp. 2619-2626, 2005.

[15] E. P. Ryan, S. J. Pollock, K. Kaur et al., "Constitutive and activation-inducible cyclooxygenase-2 expression enhances survival of chronic lymphocytic leukemia B cells," Clinical Immunology, vol. 120, no. 1, pp. 76-90, 2006.

[16] D. Hwang, "Modulation of the expression of cyclooxygenase2 by fatty acids mediated through Toll-like receptor 4-derived signaling pathways," FASEB Journal, vol. 15, no. 14, pp. 25562564, 2001.

[17] U. Puhlmann, C. Ziemann, G. Ruedell et al., "Impact of the cyclooxygenase system on doxorubicin-induced functional multidrug resistance 1 overexpression and doxorubicin sensitivity in acute myeloid leukemic HL-60 cells," Journal of Pharmacology and Experimental Therapeutics, vol. 312, no. 1, pp. 346-354, 2005.

[18] S. G. Harris, J. Padilla, L. Koumas, D. Ray, and R. P. Phipps, "Prostaglandins as modulators of immunity," Trends in Immunology, vol. 23, no. 3, pp. 144-150, 2002.

[19] Y. Denizot, M. Donnard, V. Truffinet et al., "Functional EP receptors on blast cells of patients with acute leukemia," International Journal of Cancer, vol. 115, no. 3, pp. 499-501, 2005.

[20] E. Malissein, S. Reynaud, D. Bordessoule et al., "PGE 2 receptor subtype functionality on immature forms of human leukemic blasts," Leukemia Research, vol. 30, no. 10, pp. 1309-1313, 2006.

[21] B. Müller, "Pharmacology of thromboxane $A_{2}$, prostacyclin and other eicosanoids in the cardiovascular system," Therapie, vol. 46, no. 3, pp. 217-221, 1991.

[22] C. Vincent, R. Fiancette, M. Donnard et al., "5-LOX, 12-LOX and 15-LOX in immature forms of human leukemic blasts," Leukemia Research, vol. 32, no. 11, pp. 1756-1762, 2008.

[23] K. Matsumoto, I. Morita, and S. Murota, "Arachidonic acid metabolism by nuclei of a retinoic acid - or vitamin D3differentiated human leukemia cell line HL-60," Prostaglandins Leukotrienes and Essential Fatty Acids, vol. 51, no. 1, pp. 51-55, 1994.

[24] M. Zaitsu, E. Ishii, and Y. Hamasaki, "Induction of thromboxane $\mathrm{A}_{2}$ synthesizing enzymes in DMSO-induced granulocytic differentiation of HL-60 cells," Prostaglandins Leukotrienes and Essential Fatty Acids, vol. 67, no. 6, pp. 405-410, 2002.

[25] S. Pawate, K. L. Schey, G. P. Meier, M. E. Ullian, D. E. Mais, and P. V. Halushka, "Expression, characterization, and purification of C-terminally hexahistidine-tagged thromboxane $\mathrm{A}_{2}$ receptors," Journal of Biological Chemistry, vol. 273, no. 35, pp. 22753-22760, 1998.

[26] H.-W. Shen, Y.-L. Chen, C.-Y. Chern, and W.-M. Kan, “The effect of prostacyclin agonists on the differentiation of phorbol ester treated human erythroleukemia cells," Prostaglandins and Other Lipid Mediators, vol. 83, no. 3, pp. 231-236, 2007.

[27] R. Fiancette, C. Vincent, M. Donnard et al., "No effect of $\mathrm{PGI}_{2}$ and $\mathrm{TXB}_{2}$ on the proliferation of immature forms of leukemic blasts," Leukemia Research, vol. 33, no. 4, pp. 596-598, 2009.

[28] S. W. Crooks and R. A. Stockley, "Leukotriene B4," International Journal of Biochemistry and Cell Biology, vol. 30, no. 2, pp. 173-178, 1998.

[29] Y. Wen, J. Gu, S. K. Chakrabarti et al., "The role of 12/15lipoxygenase in the expression of interleukin- 6 and tumor necrosis factor- $\alpha$ in macrophages," Endocrinology, vol. 148, no. 3, pp. 1313-1322, 2007.

[30] L. Huang, A. Zhao, F. Wong et al., "Leukotriene B4 strongly increases monocyte chemoattractant protein-1 in human monocytes," Arteriosclerosis, Thrombosis, and Vascular Biology, vol. 24, no. 10, pp. 1783-1788, 2004.

[31] G. Runarsson, S. Feltenmark, P. K. A. Forsell, J. Sjöberg, M. Björkholm, and H.-E. Claesson, "The expression of cytosolic phospholipase $\mathrm{A}_{2}$ and biosynthesis of leukotriene B4 in acute myeloid leukemia cells," European Journal of Haematology, vol. 79, no. 6, pp. 468-476, 2007.

[32] S. Feltenmark, G. Runarsson, P. Larsson, P.-J. Jakobsson, M. Bjorkholm, and H.-E. Claesson, "Diverse expression of cytosolic phospholipase $\mathrm{A}_{2}$, 5-lipoxygenase and prostaglandin $\mathrm{H}$ synthase 2 in acute pre-B-lymphocytic leukaemia cells," British Journal of Haematology, vol. 90, no. 3, pp. 585-594, 1995.

[33] L. Stenke, M. Sjölinder, T. D. Miale, and J. Å. Lindgren, "Novel enzymatic abnormalities in AML and CML in blast crisis: elevated leucocyte leukotriene $\mathrm{C}_{4}$ synthase activity paralleled by deficient leukotriene biosynthesis from endogenous substrate," British Journal of Haematology, vol. 101, no. 4, pp. 728736, 1998.

[34] V. Desplat, Z. Ivanovic, F. Dupuis, J.-L. Faucher, Y. Denizot, and V. Praloran, "Effects of lipoxygenase metabolites of arachidonic acid on the growth of human blood CD $34^{+}$ progenitors," Blood Cells, Molecules, and Diseases, vol. 26, no. 5, pp. 427-436, 2000.

[35] J. W. Chung, G.-Y. Kim, Y.-C. Mun, J.-Y. Ahn, C.-M. Seong, and J.-H. Kim, "Leukotriene B4 pathway regulates the fate 
of the hematopoietic stem cells," Experimental and Molecular Medicine, vol. 37, no. 1, pp. 45-50, 2005.

[36] A. M. Tager and A. D. Luster, "BLT1 and BLT2: the leukotriene $\mathrm{B}_{4}$ receptors," Prostaglandins Leukotrienes and Essential Fatty Acids, vol. 69, no. 2-3, pp. 123-134, 2003.

[37] F. Bussolino, R. Foa, F. Malavasi, M. L. Ferrando, and G. Camussi, "Release of platelet-activating factor (PAF)-like material from human lymphoid cell lines," Experimental Hematology, vol. 12, no. 9, pp. 688-693, 1984.

[38] R. Foa, F. Bussolino, M. L. Ferrando et al., "Release of plateletactivating factor in human leukemia," Cancer Research, vol. 45, no. 9, pp. 4483-4485, 1985.

[39] Y. Denizot, F. Dupuis, F. Trimoreau, V. Praloran, and E. Liozon, "Decreased levels of platelet-activating factor in blood of patients with lymphoid and nonlymphoid hematologic malignancies," Blood, vol. 85, no. 10, pp. 2992-2993, 1995.

[40] S. Ishii and T. Shimizu, "Platelet-activating factor (PAF) receptor and genetically engineered PAF receptor mutant mice," Progress in Lipid Research, vol. 39, no. 1, pp. 41-82, 2000.

[41] A. M. Marrache, F. Gobeil Jr., S. G. Bernier et al., "Proinflammatory gene induction by platelet-activating factor mediated via its cognate nuclear receptor," Journal of Immunology, vol. 169, no. 11, pp. 6474-6481, 2002.

[42] M. Donnard, L. Guglielmi, P. Turlure et al., "Membrane and intracellular platelet-activating factor receptor expression in leukemic blasts of patients with acute myeloid and lymphoid leukemia," Stem Cells, vol. 20, no. 5, pp. 394-401, 2002.

[43] W. E. Berdel, E. Kulimova, A. Kolkmeyer et al., "Receptor for platelet-activating factor (PAF) Is not detectable by flow cytometry on the surface of myeloid leukemic cells," Annals of Hematology, vol. 84, no. 12, pp. 771-773, 2005.

[44] N. K. Hopkins, A. H. Lin, and R. R. Gorman, "Evidence for mediation of acetyl glyceryl ether phosphorylcholine stimulation of adenosine 3',5' (cyclic)monophosphate levels in human polymorphonuclear leukocytes by leukotriene B4," Biochimica et Biophysica Acta, vol. 763, no. 3, pp. 276-283, 1983.

[45] F. D. Beusenberg, I. L. Bonta, and J. G. C. Van Amsterdam, "Cyclic-AMP level and eicosanoid release from alveolar macrophages are differentially affected by high and low dose of platelet activating factor," Biochemical Pharmacology, vol. 47, no. 3, pp. 588-590, 1994.

[46] Y. Denizot, M. Donnard, V. Truffinet et al., "Platelet-activating factor does not stimulate cAMP formation from immature forms of freshly isolated leukaemic blasts," Leukemia and Lymphoma, vol. 46, no. 1, pp. 129-131, 2005.

[47] T. T. Amatruda III, N. P. Gerard, C. Gerard, and M. I. Simon, "Specific interactions of chemoattractant factor receptors with G-proteins," Journal of Biological Chemistry, vol. 268, no. 14, pp. 10139-10144, 1993.

[48] S. Reynaud, E. Malissein, M. Donnard et al., "Functional platelet-activating factor receptors in immature forms of leukemic blasts," Leukemia Research, vol. 31, no. 3, pp. 399402, 2007.

[49] V. Truffinet, C. Vincent, M. Donnard et al., "No effect of platelet-activating factor on the proliferation and apoptosis of immature forms of leukemic blasts," Leukemia Research, vol. 31, no. 12, pp. 1766-1768, 2007.

[50] E. Müller, G. Dupuis, S. Turcotte, and M. Rola-Pleszczynski, "Human PAF receptor gene expression: induction during HL60 cell differentiation," Biochemical and Biophysical Research Communications, vol. 181, no. 3, pp. 1580-1586, 1991.
[51] C. Cellai, A. Laurenzana, E. Bianchi et al., "Mechanistic insight into WEB-2170-induced apoptosis in human acute myelogenous leukemia cells: the crucial role of PTEN," Experimental Hematology, vol. 37, no. 10, pp. 1176-1185, 2009.

[52] F. Paoletti, "Platelet-activating factor and acute myelogenous leukaemia (response)," Experimental Hematology, vol. 38, pp. 435-436, 2010. 


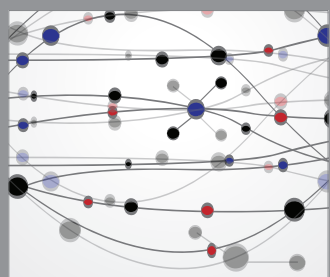

The Scientific World Journal
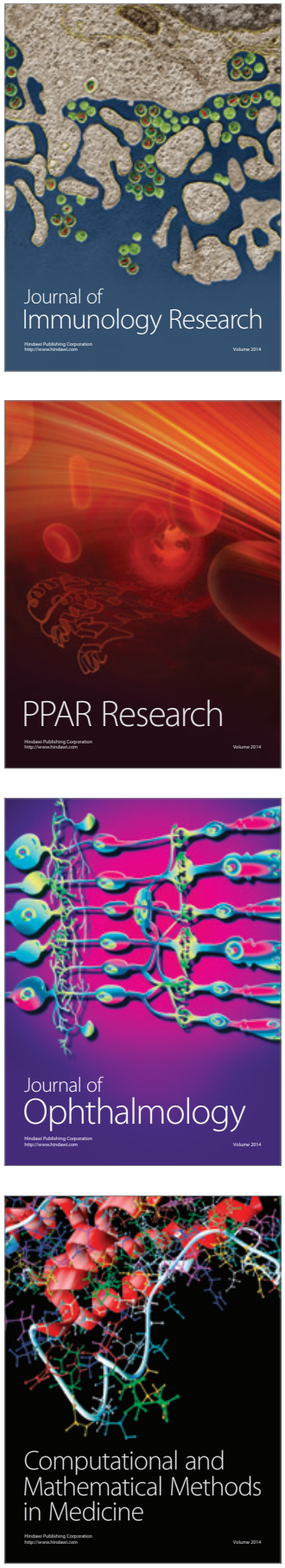

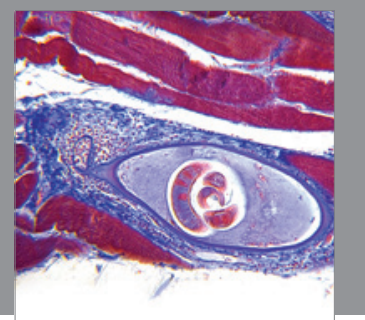

Gastroenterology

Research and Practice
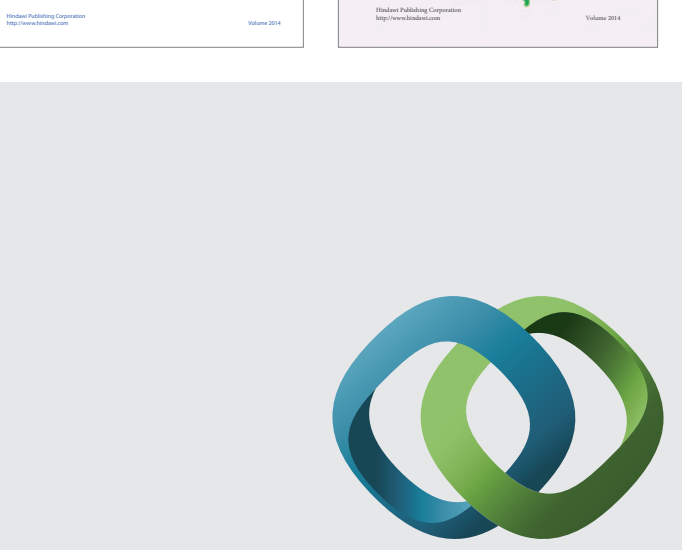

\section{Hindawi}

Submit your manuscripts at

http://www.hindawi.com
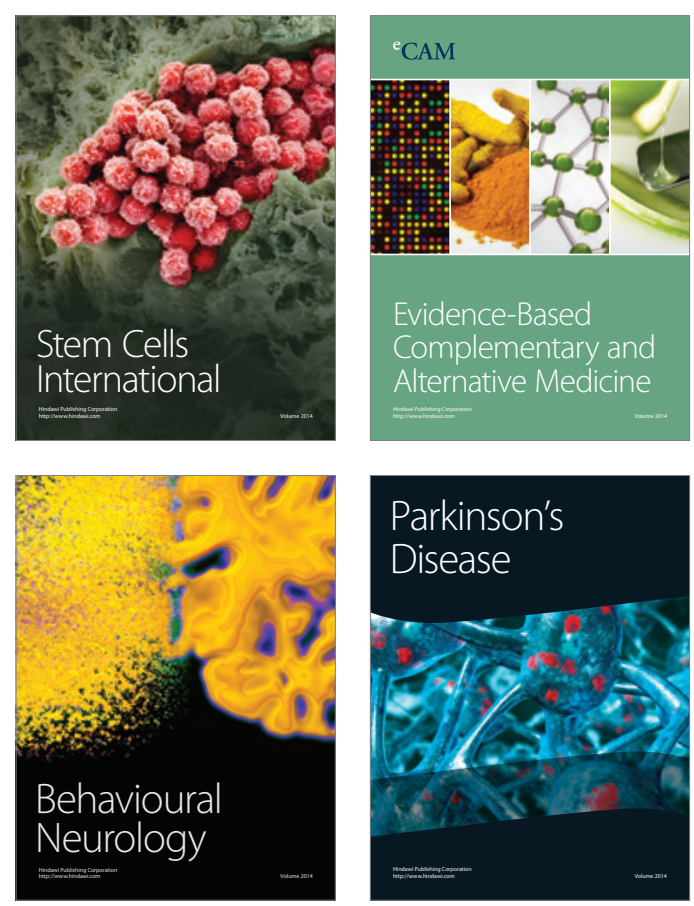

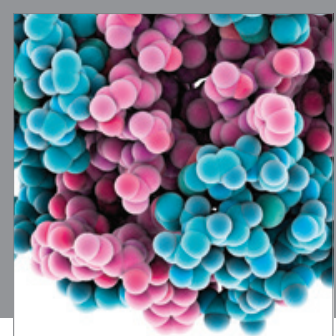

Journal of
Diabetes Research

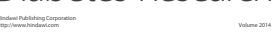

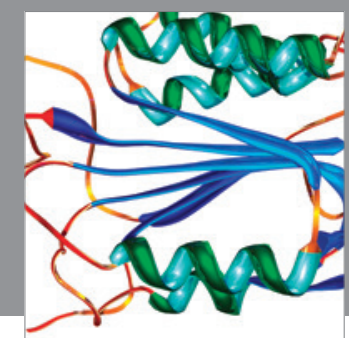

Disease Markers
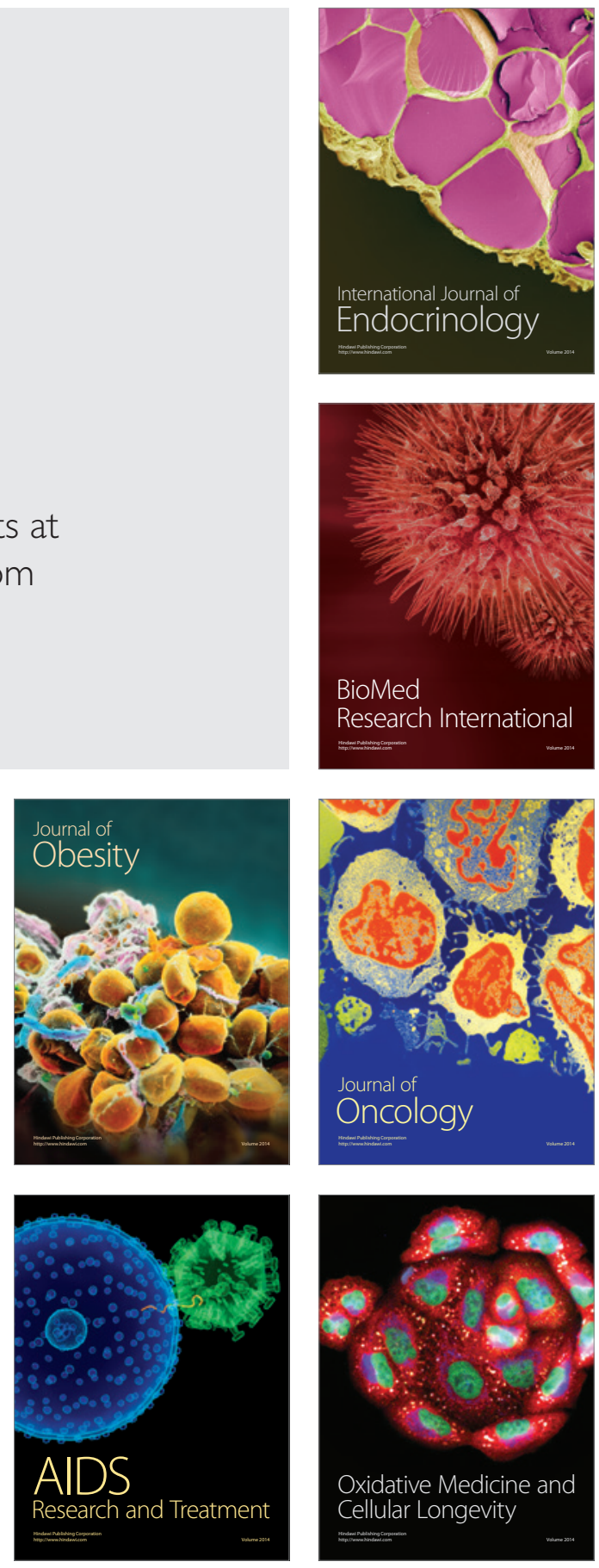